\title{
RESEARCH COMMITTEE ON FRICTION.
}

\section{SECOND REPORT ON FRICTION EXPERIMENTS.}

\author{
By Mr. BEAUCHAMP TOWER, OF LoNdon.
}

\section{Experiments on the Oil Pressure in a Bearing.}

These experiments were tried with a brass similar to that which had been used for the Friction Experiments previously conducted by the Research Committee of this Institution (see Proceedings 1883, pp. 638-9). The bearing was 4 inches diameter and 6 inches long. The brass did not embrace quite half the journal, having been reduced till the chord of the arc of contact was 3.9 inches, as shown in Figs. 1 and 2 in the accompanying Plate facing page 60.

Three $\frac{1}{4}$-inch holes wore drilled lengthwise in the body of the brass, and through a little more than half its length, Fig. 1. One of them was in the centre, and the other two were one on each side of it, Fig. 2. These holes coming out at one end of the brass were connected by converging copper pipes to a Bourdon pressure-gauge. In order to ascertain the pressure at any point between the brass and journal, a hole $\frac{1}{16}$ inch diameter was drilled from the bearing surface of the brass into one of these longitudinal holes, thus establishing a connection between that point and the pressure-gauge. The pressuro having been ascertained, the hole was stopped and another hole drilled, and so on.

The arrangement of the holes which were successively tested was as follows. The brass was supposed to be divided by six vertical planes, three of them parallel to the axis of the journal, and three at right angles to it; and the test holes were situated at the nine points of intersection of these planes. The planes parallel to the axis of the journal were 0.975 inch apart, Fig. 2 , so as to divide the brass longitudinally into fuir parts of equal breadth. Of these three planes, one passed along the axis of the journal, and was called the "centre plane." One was on the side where the surface of the 
journal entered the brass, and was called the "on plane," the direction of rotation of the journal being indicated by the arrow in Fig. 2. The other on the side where the surface of the journal left the brass was called the "off plane." Of the three transverse planes, Fig. 1, one was in the centre of the length of the brass, and was called the "middle plane;" the other two were each one inch apart, and divided the brass from the middle to the end into three transverse slices of one inch length. The plane nearest the middle was called No. 1, and the furthest No. 2. The position of any one of the nine holes can thus be easily described by naming the two planes at the intersection of which it was situated.

The pressure was thus actually read off at nine places in the bearing; but as it is reasonable to suppose that the pressure must be symmetrically disposed on either side of the middle transverse plane, Fig. 1, the pressures were observed on one side only of that plane, and those on the other side were assumed to be the same: so that in reality the pressure may be considered to have been ascertained in fifteen places distributed over the whole bearing surface of the brass.

The bearing had a total load of $8,008 \mathrm{lbs}$. on it, and the journal rotated at 150 revolutions per minute. The temperature throughout was $90^{\circ} \mathrm{Fahr}$. The observed oil pressures were as follows in lbs. per square inch.

TABLE XII._Oil Pressure at different points of a Bearing.

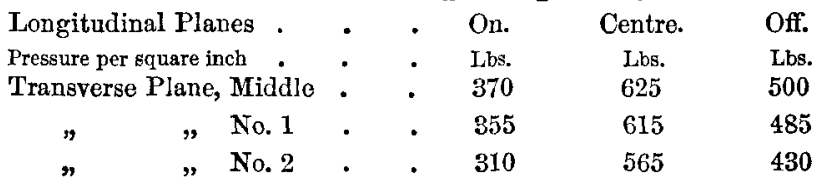

Curves drawn by using these figures as ordinates are shown in Figs. 1 and 2 in the accompanying Plate. Their most clearly marked feature is seen to be that the place of greatest pressure is on the "off" side of the centre, Fig. 2, the pressure at the holes in the "on" side being in every case considerably less than that at the corresponding holes on the "off" side. The total upward force exerted by these pressures is 7,988 lbs., or within $20 \mathrm{lbs}$. of the actual load of $8,008 \mathrm{lbs}$; this very small difference between the load and the oil pressure is probably due to errors of observation. 
In order to wear the brass down to a perfect fit on the journal, the bearing was first run for some time with a heavier load than that with which the experiments were taken. It was found that in taking off or putting on weight the pressure fell or rose exactly in proportion to the load. At the end of the experiments the speed of the journal was reduced from 150 revolutions per minute to 20 ; but the pressure-gauge indicated exactly the same pressure with both speeds.

The oil used was a heavy mineral oil, the journal being about half immersed in a bath of it.

\section{Experiments on Friction at a Low Speed.}

After the completion of the oil-pressure experiments, the speed was reduced to 20 revolutions per minute; and observations of the nmount of friction at this speed with various loads were made with the journal running about half immersed in a bath of mineral oil. By this time the brass had become by wear a very perfect fit on the journal : so perfect that, after stopping the journal, the pressure indicated by the pressure-gauge fell very slowly; on one occasion it took about half an hour for the pressure to fall from $600 \mathrm{lbs}$. per square inch to zero. The pressure indicated by the pressure-gauge at 20 revolutions per minute was the same as that at 150 , thus showing that the brass was as completely oil-borne at the lower speed as it had been at the higher.

The frietion was very nearly the same as that obtained in the former experiments with the same kind of oil at 200 revolutions per minute. The following was the observed frietion.

TABLE XIII.-Friction of a Bearing 4 inches diameter and 6 inches long, running at 20 revolutions per minute in a bath of Mineral Oil.

Chord of arc of contact of brass, $3 \cdot 9$ inches. Temperature $90^{\circ} \mathrm{F}$.

Nominal Load.

Lbs. per sq. inch.

443

333

211
Coefficient of Friction at 20 revs. $=21$ feet per min.

$$
\begin{aligned}
& 0.00132 \\
& 0.00168 \\
& 0.00247 \\
& 0.0044
\end{aligned}
$$




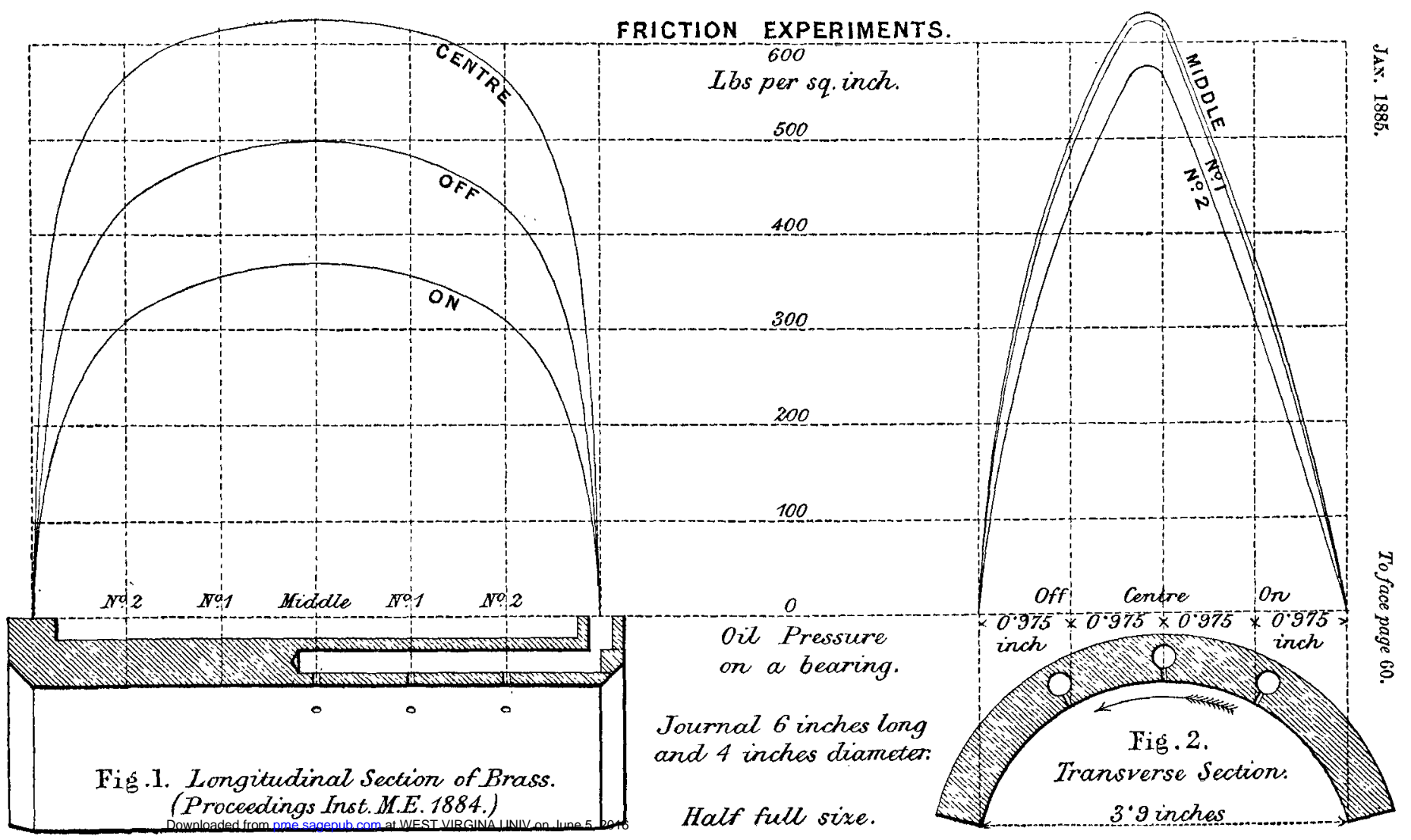


Downloaded from pme.sagepub.com at WEST VIRGINA UNIV on June 5, 2016 
From these figures it is seen that, while the load was reduced from $443 \mathrm{lbs}$. down to $89 \mathrm{lbs}$. per square inch, or in the ratio of 5 to 1 , the coefficient of friction rose from 0.00132 up to 0.0044 , or in the ratio of 1 to $3 \frac{1}{3}$.

The nominal load per square inch is the total load divided by the product of the diameter and length of the journal ; that is to say, it is in this case 1-24th of the total load. At the same low speed of 20 revolutions per minute it was increased to $676 \mathrm{lbs}$. per square inch without the slightest signs of heating or seizing.

\section{Discussion.}

Mr. Joseph Tomlinson explained that the first series of experiments (Proceedings 1883, pp. 632-652) had led to the second now deseribed, in consequence of the difficulty which had been experienced of feeding the journal with lubricating material from the top, when there was a heary load on the bearing. It had then been suggested by Mr. Tower and himself that they shonld find out what the pressures were in an upward direction; and the present Report simply recorded the results of the experiments made with this object. It was very interesting to discover that, after the load on the bearing had risen to something like 200 lbs. per square inch, the oil could no longer be fed from the top; it would not then go down, and the bearing seized almost immediately. But by oiling from the bottom the load had been increased up to 625 lbs. per square inch, by putting on all the load that could be got into the framework of the experimental apparatus, and at high velocities they had succeeded in running with that load; but when it was again attompted to feed from above, the efforts entirely failed with the heavy load that had been put on. That was the way in which this second series of experiments had originated, and he thought the results were very interesting. The chief advantage derived from the experiments was that they showed that, if the bearing was perfectly lubricated by immersion in a bath, almost any load might be put on. 
Mr. Beauchamp Tower said the experiments detailed in the Report that had just been read were supplementary to the former experiments, in which the curious discovery had been made that between the brass and the journal there was an actual oil pressure which could be indicated by a pressure-gange. A remarkable confirmation was thereby afforded of the theoretical conclusion to be derived from the previous experiments, namely, that it was possible to make the brass on a journal work so nicely that there should be absolutely no metallic contact between the journal and the brass, the whole of the weight being borne by the oil. It seemed to him that the important practical inference was that it was actually possible so to lubricate a bearing that not only would metallic friction be altogether done away with, and thereby the amount of power lost by friction be reduced, but metallic wear and tear would also be done away with. He would not say that such a result was actually possible in practice now; but it was a reasonable one to aim at in mechanism. By giving a sufficiently profuse lubrication, and by having the brasses so arranged that there should be a uniform pressure all over their surface, it was possible to have wear and tear between metal and oil, instead of between metal and metal.

Mr. Charles Cochrate mentioned that in a recent visit to the North Eastern Railway locomotive and wagon shops at Darlington he had noticed a plan there adopted for getting over this difficulty of feeding the axles from the top. The journals were there boxed in underneath in such a way as to allow of supplying to the underside of the journal the oil necessary for lubricating. He had mentioned the fact of these friction experiments to the engineer, who had been much pleased to find that the plan which he himself had applied practically was borne out theoretically.

Mr. JoHN Robinsor could confirm from experiments made long ago what Mr. Tower had said about avoiding actual metallic contact, by the oil preventing contact between the brass and the iron. This avoidance of contact by an intervening fluid had fallen under his own observation many years ago, when set during his apprenticeship to 
file and scrape surface-plates. His old master, Mr. Roberts, as was well known, was a very exact mechanic; and one thing that he set his apprentices to do was to produce very accurate surfaces. They had at that time surface-plates weighing perhaps $25 \mathrm{Ibs}$. each, and ho had often seen one plate put on the other-as no doubt many other engineers had seen too-when no contact existed between the upper and the lower plate, the upper being wholly floated upon a stratum of air which remained between the two surfaces; and if air would so resist that pressure, it was much more easy for oil to do so.

Mr. Daniel Adamson had had some experience in the lubricating of journals, and under very much heavier pressures than those mentioned in the Report. Under ordinary circumstances he should not think there would be much difficulty in carrying out the Iubrication of a journal from beneath, as now recommended from these experiments ; but it had been pointed out in the Report, and he thought most excellently, that with an exceedingly well fitting journal there was a difficulty to get oil in between. It was generally recognised that the oil acted as a lubricant by merely furnishing atoms rolling in between the two surfaces; but unless the atoms could be got in between, there was no possibility of the diminution of friction. The most difficult case was that of Iubricating the footstep of an upright shaft carrying a heavy load. Supposing there were an upright shaft of 5 inches diameter, or say 20 square inches area, then in practice 20 tons could certainly be carried on the footstep of such a shaft; and 2240 lbs. per square inch was a very different thing from the limited pressures mentioned in the Report. But in such a case, instead of using thin mineral oil, he would mix fatty oil with the mineral oil, so as to get it more manageable. His latest experience, which had been very satisfactory both to himself and to others, was not to attempt to oil at the top a bearing under heary pressure, because practically, as was set forth in the Report, the oil could not be got in so. If the difficulty was to be entirely got over, the oil must be got in at tho bottom, and for that purpose a pump must be used. By that mcans the difficulty of working an upright shaft under a very heavy load, and at much higher speed 
(Mr. Daniel Adamson.)

than the revolutions reported in the paper, was very easily got over. Tho oil should bo put in at the centrc of the footstep of an upright shaft, because the centrifugal action had a tendency to run it to the outside; and it was clcar that the first supply of the oil to the metal surfaces should be at the point where it was most needed. He had tried to get the oil underneath the foot of the upright shaft, when running with anything like one ton por square inch, by means of a surrounding cistorn of oil, and had failed many times. The system of feeding by pump was neither difficult nor expensive, because the same oil was pumped in over and over again, and the heavily pressed journal would go on working well, and very little expenditure of oil would take place. This had been his own drily experience, the pump having been the means of obviating the whole trouble of such hcavily loaded journals, where previously the lubricant could not bo got into the right place.

Mr. Williay Schönhexden asked whother tho friction experiments wero going to be continued, and if so whethor cxperiments ought not to be made upon journals more heavily loaded than those mentioned in the Report. Engineers all liked to provide very liberal journals and to have very light loads per square inch, but it was not always possible to do so; and they would like to know how journals behaved when weighted with heavier loads than 600 lbs. per square inch.

Another point which he considered ought to be brought moro clearly to light was the difference between the load a journal could carry when the load was continuously on it, as for instance in tho axles of railway carriages, and when the load was intermittent. It was woll known from practical experience that with a constant load on an ordinary journal it was difficult and almost impossible to havo more than 200 lbs. per square inch, otherwise the bearing would get hot and the oil go out of it; but when the motion was reciprocating, so that the load was alternately relieved from the journal, as with crank-pins and similar journals, much highor loads might be applied than evon 700 or $800 \mathrm{lbs}$. por square inch. If these experimonts 
were to be continued, it seemed to him that it would not be difficult to have the load intermittently relieved from the bearing, and in that way to find out what the friction then was and what loads could actually be carried.

Mr. Edward Reynolds said, with regard to Mr. Robinson's observation about surface-plates floating on the air held between them, the converse of that also existed. It was very easy indeed to get rid of that film of air, and then the plates stuck together. As much as forty years ago he had found out that it was easy to make the slide-blocks of locomotives too long, because the leading part of the blocks then swept away the oil, and left the tail part dry. That was now got over by grooving; and within his own knowledge it had been found necessary to groove the journals of axles, as well as their brasses, so that the groove in the journal might have a chance of picking up the oil as it passed, and of carrying it from the bottom up into the bearing or from groove to groove in the brass. A friend had one day called his attention to a case bearing strongly upon this point, when he happened to be looking at some planing machines made with flat beds, for the sake of having rectangular sides to the bed for resisting side cuts. His friend seeing those machines had advised him to have the faces scraped of the beds; and on his remonstrating that they could not be a better fit than they then were, the reply he received was "That is exactly what is the matter; it is too gooa a fit." There were very many cases of slide-bars and rubbing surfaces of that kind, which worked on for ever so many years before the scraper marks were gone; and then all at once they began to cut, because the scraper marks were gone. It did not do to have exceedingly well-fitting surfaces, for high speeds at any rate. It was exceedingly difficult to keep the film of lubrication in; and that was the object always to be aimed at. The fact had been known in the abstract for a long time that a surface could be floated on a film of liquid, or even of air, interposed between itself and another surface; the difficulty was to point ont some means by which that fact could be practically ntilised. 
Mr. Georar Richards observed that neither in the Report, nor thus far in the discussion upon it, had any reference been made to the life of the oil used for lubrication. This would of course be modified by the nature of the oil used: that is, whether it was a mineral oil, or whether of animal or vegetable origin. Animal and vegetable oils underwent a gradual chemical change when exposed for a long time in thin films to the air; their glycerine was separated, and they were converted into fatty acids. Several years ago somo experiments had been tried by Mr. Isherwood, of the United States Navy, in which the power developed by steam engines was tested by making them drive a number of fans at a certain speed. The hearings of the fans were kept flooded with lard oil, and the overflowing oil was filtered and used over and over again for several months. A doubt having been suggested as to whether tho Iubricating power of this oil remained unchanged in its repeated use, the experiment was tried of replacing it by fresh oil, all other conditions remaining the same. The speed of the fans was observed to increase immediately; and after a fow minutes, when the fresh oil had completely displaced the old in the bearings, another fan had to be thrown on in order to bring the speed down to its normal rate. It would seem therefore that in the case of lard oil, and probably of all animal and vegetable oils, the freshness of the oil had a considerable influence upon its lubricating power.

Mr. Joseph Tomunson said, in reference to the life of oil, he had had a carriage running until a few months ago on the Metropolitan Railway with brass bearings, which had run about 29,000 miles a year with the same bearings for ten years; and the average amount of oil put in during the whole time was one pint per annum per journal. The journals were lubricated from the bottom。*

The Prisident pointed out that in these experiments a kind of bearing had been selected which was not the most frequent in general use, namely a hanging bearing, that is, a bearing going over the top

* Proceedings Institution of Civil Engineers, 1878, vol, liii, page 86 . 
of a shaft, which shaft also was quietly revolving. The axle-boxes in railway trains differed, in that they were all in a state of vibration, which probably allowed the oil to pass freely round. There were very few examples in ordinary work where the bearing was on the top, with a heavy load hanging from it, and without any vibration whatever. The Report, though brief, he thought was a very valuable one; and he for one certainly trusted that the Friction Committee would continue their investigations. They had quite revolutionised in many ways the notions that had previously prevailed with regard to friction. He remembered when a student that the experiments of the late General Morin were those which were generally quoted. In those experiments several different metals were taken, and after their surfaces had been oiled they were wiped nearly dry and were then experimented upon to find what the friction was. Roughly speaking it was something like one-tenth of the load; as the load increased or diminished, the friction on the same surface was supposed to increaso or diminish in the same proportion. The point was that the surfaces were always wiped nearly dry after being oiled. In a note appended to the account of those early experiments it was mentioned that if the bearing was fully supplied with oil it was more a question of the nature of the oil than of the nature of the metals. The experiments described in the present Report seemed rather to confirm that view, because if the bearing was entirely oil-borne the question would naturally be asked, "Does it really matter what the bearings are made of?" These experiments would have been quite a failure if the device had not been hit upon of making the bearing revolve in a bath of oil below. That made all the difference between the impossibility of lubricating the journal at all, and the ability to do it in such a way as to float it in oil altogether. This result was extremely suggestive, and might lead to a revolution in the way of oiling bearings. It gavo still more importance to the nature of the oil used, when it was found that the bearings were oil-borne. As Mr. Adamson had pointed out, the same conclusion seemed to have been arrived at by others. Oil had in several cases been pumped continuously into bearings in such a way as to keep them floating in oil. He believed the Hon. Mr. Parsons did this in his fast-running engino mado at Mossrs. 
(The President.)

Kitson's at Leeds; and Mr. Heenan also did it in the inside of the Tower spherical engine. He thought the Members would all agreo that these experiments upon friction had proved most valuable, and that it was most desirablo they should bo continued.

Mr. Arthor Paget asked the President's permission to say that he thought they should not be fulfilling their duty if they did not pass a hearty vote of thanks to the gentleman who had done tho major part of the work and had contributed so largely to the success of the Committee's experiments. He alluded to Mr. Tomlinson, who had conducted the experiments almost at his own cost, and had given an amount of time and devotion to the subject which he was suro the Institution would gladly recognise. He therefore proposed that a vote of thanks be given to Mr. Tomlinson for his valuable labours, which had resulted in the Report that had just been read.

The President had great pleasure in putting the motion, which he thought was most opportune and well merited.

The motion was carricd unanimously. 